\title{
EMERGENCIES IN GENERAL PRACTIGE
}

\section{ELECTRIC SHOCK AND ASSOCIATED ACCIDENTS}

BY

\author{
J. P. W. HUGHES, T.D., M.D., D.P.H. \\ Formerly Lecturer in the Nuffield Department of Occupational Health, University of Manchester
}

The number of electrical accidents occurring outside industry is unknown. About 100 deaths are ascribed to electricity by the Registrar-General annually, and about a quarter of these occur in industry, where there are about 750 reportable (three or more days' absence) accidents annually. The increased usage of electricity, in industry at least, has resulted in both lower accident and lower mortality rates. At the turn of the century $17 \%$ of industrial electrical accidents were fatal compared with $6 \%$ between 1920 and 1930, and $4 \%$ now.

\section{Types of Accident}

Three effects of electricity may cause damage to the body: the effect of the current itself, the effect of the power being converted into light, and the effect of the power being converted into heat. The last may be subdivided into electrical necrosis and simple burning from the flash of an arc.

Effect of the Current: "Electric Shock."-The general practitioner sees most commonly one of two types of case. The first is where the victim is apparently dead and his mates have sent for the doctor. This type of accident is particularly apt to be associated with falls from heights, so that other injuries may be present as well. The patient is pulseless and may present no external evidence that a current has passed through him, or there may be a varying degree of electrical necrosis of the parts of the body which have been in contact with the current. In addition, flash from an arc may have scorched the skin or set the clothes on fire. The other common occurrence is where a man reports some hours later that he has been "shocked." $\mathrm{He}$ is usually in some distress, pale and sweating, and may be in a state of acute fear. Some of the immediate after-effects may be present, particularly stiffness from muscle spasms, headache, burns, and arc-eye. Less often the patient is seen days or months later presenting with a syndrome which may not be obviously related to the accident. Occasionally a general practitioner may be called upon to deal with persons struck by lightning.

Electricity Converted into Light: "Arc-eye."-Arc-eye may occur from the intense light generated by an arc, but it is rarely severe, being usually overshadowed by the effects of burning. Further damage to the eye can occur as a result of the deposition of metal in the conjunctivae. This is caused by incandescent copper vapour from the electrode depositing itself over the exposed surfaces of the body when an arc is struck.

Effects of Heat.-(1) "Electrical Necrosis": Burning of tissues by a current is usually minor in the home or factory. The effect is most pronounced in tissues that have the greatest resistance and is therefore usually limited to the skin. With very high voltages and large currents, however, the damage may be great and affect all tissues with sometimes total loss of members. (2) Burns from an Arc: These are burns caused by the intense heat of the arc, which scorches the exposed parts. They may be very minor, such as would occur if live wires in a household supply were cut across with scissors, or may, in the common type of accident with switchgear in power-stations or substations, burn all the exposed skin and set hair and clothing alight. Metallization of the skin may occur if the whole skin thickness has not been lost.

\section{Basic Physics and Physiology}

The amount of current passing through a body is dependent on voltage and resistance (Ohm's law*). Voltages vary in this country from 275,000 volts downwards (excluding surges) and the resistance of the body is very variable. As well as the amount of current two other qualities determine the physiological effects in the body: first, whether the current is alternating (A.C.) or direct (D.C.), and, second, if alternating, the number of alternations a second.

Electricity is generated at 50 cycles a second, and ironically this gives the number of alternations which produce the maximum physiological effect. A.C. has superseded D.C. because it can be transformed into lower voltages more easily; and the number of cycles is determined by the lowest number which will give the effect of a continuous current so that flickering of lights, etc., is obviated. The raising of the number of cycles results in uneconomic dissipation of the current in heat.

Electricity travels at 186,000 miles $(300,000 \mathrm{~km}$.) a second and a nerve impulse at about 120 metres a second (in man). A nerve impulse is not a true current but a physico-chemical process involving the transfer of positively charged sodium ions through the nerve membrane and the neutralization of the external negatively charged potassium ions. In medullated nerves this process occurs only at the nodes of Ranvier, the internodal gaps being jumped by a true current. A nerve impulse is therefore no more a current than an accumulator carried along a passage is a current along that passage.

Nerves are not particularly good conductors of electricity. It has been estimated that one inch $(2.5 \mathrm{~cm}$.) of the sciatic nerve has the same resistance as the whole of the Atlantic cable. Currents, therefore, may travel in all tissues and act on the motor end-plates directly. On reaching the motor end-plate both an impulse and a current act in the same way. Acetylcholine is released in bridging the gap between nerve and muscle, and, pending its destruction by cholinesterase, the system is in a refractory period. Since at 50 cycles a second the current flows either way for $1 / 100$ of a second, the nerve-muscle system is still in a refractory period at the time of the next impulse. Consequently with A.C. muscles remain in spasm, and a man becomes "locked" to the apparatus. Direct currents cause momentary locking at make-and-break but not continuous spasm. If the frequency is raised, the body is able to tolerate more current but the "shock" effect is detectable up to about 50 kilocycles a second. Above this frequency only heat is experienced, as, for instance, in diathermy, where a million or more cycles a second are used. The significance of the number of cycles is shown in the experiment where a man holding an electrode in either hand can, with short-wave $\dagger$ currents (10 or more megacycles $\ddagger$, complete a circuit and light an electric bulb. This would be both dangerous and unpleasant at 50 cycles. A.C. is again more dangerous than D.C. in that the figure of, say, 230 volts is the R.M.S. (root

* Ohm's law : the current in amperes (I) equals the voltage in volts $(E)$ divided by the resistance in ohms $(R)$. $I=E / R$.

$\dagger$ As electricity travels at 186,000 miles $(300,000 \mathrm{~km}$.) a second, if the number of cycles is increased, the waves shorten. At 50 cycles a wave is 3,720 miles $(6,000 \mathrm{~km}$.) long and at $10 \mathrm{mega-}$ cycles it is 30 metres long.

$\ddagger 1$ megacycle $=1,000,000$ cycles. 
mean square) value of the peak voltage attained in each impulse. The peak is therefore $230 \sqrt{ } 2$, or 325 volts.

While it is safe to touch one lead of an electric supply of 230 volts when standing on a dry carpet, if this is done when in a bath death is instantaneous. This is because of the difference in the body's resistance under the two circumstances. Electrocution has occurred in a number of cases from badly earthed apparatus being used in conjunction with sinks; if the hands are wet the skin resistance is lowered and a good earth is made through the water and piping. Since the course of a current in the body is generally the most direct route through it, an electrician may often touch the two wires of a supply with two fingers of the same hand (not both hands) in order to test whether the point is alive. The current here travels up one finger and down the other without affecting the arm muscles.

By using two hand electrodes it is possible to measure in an individual the voltage at which he can still release himself, the "let-go" voltage. This varies in individuals from about 15 to 90 volts, depending on the resistance of the skin. The current at which a person can let go is in the smaller range of 8 to $14 \mathrm{~mA}$. From these figures the resistance of the body from hand to hand may be calculated, and about $3,000 \mathrm{ohms}$ is an average figure with intact healthy dry skin. But the variation is very great in practice, depending on the size of contact and other circumstances. Most of the body's resistance lies in the skin and subcutaneous fat. In electric convulsion therapy, where the pads are soaked in an electrolyte, the total biparietal resistance is between 500 and $600 \mathrm{ohms}$ (a figure so constant that it is no longer measured as a routine). Any dampening of the skin, such as sweating of the palms, will lower resistance, whilst cornification in the hands, as in a manual labourer, will raise it; and the larger the area of contact the lower the resistance.

The continued application of a current, by causing hyperaemia, sweating, vesication, and, finally, destruction of the skin, will reduce resistance so that continued contact is more dangerous than a brushing contact.

\section{Clinical Effects in Electric Shock}

Electricians describe balls of light being seen when a current is passing, the so-called "electrician's moons." After a shock a man may be apathetic or euphoric and have an acute awareness, as if due to a transitory hastening of the thought processes, with events seeming to be greatly slowed. This state of exaltation or acute perception, which is reminiscent of descriptions of mescaline intoxication, lasts for only a brief interval. More often the man is in an acute state of fear, violently trembling, pale, and sweating. Intracranial pressure is raised, probably owing to the sudden muscular spasms, and cerebral oedema may lead to unconsciousness without more than momentary cessation of respiration or of the heart. Auditory hallucinations may occur and the patient may appear blinded or deafened for a period of minutes to hours. Loss of taste may similarly be noticed. Paralysis of an affected limb for up to four hours is common, and subsequent pain and stiffness may continue for weeks or months.

The heart beat may be irregular and weakened, and a syndrome of " angina pectoris electrica" may occur, with typical pain and tightness on effort persisting for weeks, but without specific electrocardiographic changes. Sudden blindness may occur from retinal detachments, and arc-eye is usual with a major flash but usually clears up within a few days. Flaccid paralysis may develop below the level of the shock but generally resolves in two or three days.

A wide variety of late sequelae is recorded. Cataract may appear days or months later. Pain at the insertion of muscles may persist for several months. Arterial spasm in the form of effort syndrome or Raynaud's disease is not uncommon. Organic damage to the central nervous system may occur, but the pattern is bizarre and does not fit estab- lished clinical syndromes; where such syndromes have been described it is probable that shock merely drew attention to pre-existing disease.

There may be long-continued agitation, restlessness, confusion, weak heart action, and albuminuria, or dejection with low blood pressure. Confusional and psychotic states are usually temporary and may be immediate or late, and cerebral sclerosis with mental deficiency has been described. Less dramatic personality changes may occur and are said to last up to a year, but fear may have been the cause rather than electricity, and cases of prolonged disability have occurred in persons who have thought they were shocked but were not. In Berlin a man fell across the lines of an electric railway; he spent a long period in hospital with no improvement in his condition. On inquiry it was discovered that owing to a breakdown there had been no current at the time.

\section{Prognosis}

Follow-up of cases which have recovered from the immediate effects of electrocution show that severe organic lesions are rare, and even with severe lesions the ultimate prognosis is not necessarily unfavourable. Burns and falls cause most deaths with high currents, and low-current damage is usually temporary.

In fatal cases signs of external trauma are minimal and at post-mortem examination nothing may be found. Even in cases of penal electrocution in the United States, with pads applied to the head and leg and with high voltages,* surprisingly little is found at necropsy-usually no macroscopic findings, and only minute tears in the brain microscopically. In these cases the Joule $\dagger$ effect may heat the body to $130^{\circ} \mathrm{F}$. $\left(54.4^{\circ} \mathrm{C}\right.$.) and ventricular fibrillation may continue for some time after death. From this and laboratory evidence it seems likely that death in cases of electric shock without other trauma is due to ventricular fibrillation. It is unlikely to be due to paralysis of the respiratory centre, because the brain will stand $300 \mathrm{~mA}$ biparietally in electric convulsion therapy.

In animals the heart accepts $25 \mathrm{~mA}$ across it without change of rhythm. Between 25 and $75 \mathrm{~mA}$ the heart stops momentarily and then resumes an irregular beat. Between $75 \mathrm{~mA}$ and $4 \mathrm{~A}$ ventricular fibrillation occurs. Beyond this the heart locks in spasm, but it resumes a normal beat provided the current does not continue. Higher voltages (causing greater currents) are therefore not necessarily more dangerous than lower, a fact borne out by practical experience of accidents in man. Further, deliberate locking of hearts which have developed ventricular fibrillation during surgical operations is practised in the United States by putting a mains current of 120 volts A.C. (about $20 \mathrm{~A}$ ) directly through them. Experiments on sheep have shown that the heart is only vulnerable at the end of systole in the partially refractory phase which covers the $T$ wave of the electrocardiogram (about one-fifth of the cardiac cycle). Shocks occurring during other parts of the cycle do not cause fibrillation. The heart is vulnerable because currents, whether from hand to hand or hand to foot, always travel principally in the watercourses-the blood vessels - and so reach and traverse the heart.

\section{Lightning Shocks (Surges)}

About five to ten deaths from lightning occur annually in England and Wales. When a sufficient potential has been built up between clouds and earth a spark occurs which ionizes the air in front of it, making it a better conductor. The pressure (E.M.F.) of lightning is colossal, and a

* Usually 2,000 volts for a few seconds, dropped to 500 volts for a minute, raised again for a few seconds, then dropped, raised, and broken. All may be repeated several times.

$\dagger$ A current passing through a resistance causes heat; the greater the current and resistance the greater the heat (Joule's law). 
"direct" hit means instantaneous death. The person becomes highly charged, clothing is rent and blown off, and the subject may be hurled for yards. On the skin the charge tracks to earth, forming arborescent markings representing the passage of the current along trickles of rain water on the body and clothes. Depending on their distance from the force, those in the vicinity may be affected electromagnetically and experience tingling and jarring and their hair standing on end.

Survivors inside a hut have described an intensely bright light and absolute silence. The limbs are numb and stiff and tingling. Headache is intense and is followed by collapse. Great heat is generated and metal objects may melt and fuse, dental fillings become intensely hot, and in one case the coins in a man's pocket were fused together without damaging the thigh beneath.

With "near misses" considerable trauma may be applied to the body, including the appearance of the arborescent markings, but these usually fade completely with recovery. The person is rendered unconscious, may be hurled about, and may have myoclonic twitchings or tremors or lie still.

At necropsy the picture is of severe physical damage with effusions into the scalp, tears in the brain substance, and haemorrhages into the brain, serous cavities, and bladder.

\section{Electrical Necrosis}

Electrical necrosis of the skin is sharply circumscribed to the shape of the object with which contact has been made the lesion is punched-out, deep, and painless. Microscopically, in the area adjoining the necrosis the cells of the Malpighian layer may be realigned along the path of the current. Fat cells may similarly be formed into chains. These findings, when they occur, are pathognomonic of the passage of a current.

Muscles are good conductors and the current has to be large to destroy them, though ruptures may occur from the force of the contractions. Bones are poor conductors and fissure fractures may occur from heat. As in electric convulsion therapy muscular spasm may cause fractures, rupture of intervertebral disks, or lifting of periosteal attachments. Blood vessels, because of their water content, carry the greatest load and with large currents become brittle, leading to haemorrhage. Elevation of the intima is common and is believed to be pathognomonic. In injuries involving the head, dilatation of capillaries leading to cerebral oedema or to petechial or massive haemorrhages may occur. Frequently, however, death in electric convulsion therapy or accidental shock is unexplained pathologically and may be caused by a cortical stimulation leading to arrest of the heart.

Severe electrical necrosis occurs with large currents, such as accidents with switchgear in generating stations or substations or from accidentally touching overhead wires. The common accident is where a man approaches an electrode believing it to be "dead," often with a spanner in his hands, and before he has touched it the current has made an arc across from the electrode to the spanner or his flesh. This is followed by a violent explosion and mutual repulsion so that the man is blown away from the source. If he is working at a height he may be killed by the fall, but on the ground he will often be found running away from the scene of the accident. The heat generated is so great and the destruction so complete that it is often difficult to reconstruct the scene afterwards. Both spanner and electrode are vaporized and copper is deposited on the exposed parts of the face and neck. As the current arcs across from electrode to the hand it expends much of its energy in heat, and as the tool is vaporized and the flesh carbonized the current destroys its own path. The current may pass up the arm, find an exit from the shoulder, and become burnt out before it properly enters the body, so that electrocution does not take place. If electrocution does occur, death, as with lightning, is instantaneous. The necrosis may be very severe. The heat calcines bone and carbonizes flesh, and beyond the area of complete necrosis muscles are literally boiled. Occasionally groups of muscles may be spared, particularly those not in the direct path of the current. Associated with the electrical necrosis, flash burns may occur.

\section{Rescue and Treatment}

Persons struck by lightning are safe to handle immediately. In those who have suffered necrosis or shock rescue may be difficult. It may be possible to switch off, pull out a lead, or extract fuses. If a person is covering the live points, and particularly if the floor or clothing is wet, considerable circumspection is necessary to prevent two accidents replacing one. A walking-stick hooked into the axilla or a dry coat folded and used as a pad to push away a head or limb are but two methods. If such measures are of no avail, the feet should be used in direct contact rather than the hands, both because of the resistance of the footwear and because the current will not then pass directly through the rescuer's heart. Heavy rubber gloves and rubber boots in good condition are complete protection against any low voltage ; jointers frequently work in damp trenches on voltages of 400 or more whilst wearing rubber boots, taking due care, particularly in wet weather, not to touch the side of the trench.

Consciousness may be lost during the passage of the current, but after rescue it returns as muscles relax, unless the patient is in ventricular fibrillation, when he is pulseless and cyanosed. Various treatments have been suggested to arrest fibrillation, such as a sharp blow on the chest or a larger electric shock to lock the heart momentarily. In animal experiments acetylcholine injected into the ventricle arrests the heart completely and restores a normal beat. It has been suggested that, as an emergency measure, an intracardiac needle inserted through the chest wall would serve by its movements to diagnose fibrillation and allow the injection of acetylcholine. But as none of these measures can be effectively applied by workmates they are points of academic interest.

Artificial respiration is the only established treatment. It is successful in half the cases where it is administered, and success bears no relation to voltage (between 1945 and 1949 , five out of seven cases $(71 \%)$ responded when the voltage was between 5,000 and 10,000 volts). The action is cardio-respiratory, therefore movements which massage the heart are more valuable than simple pulmonary ventilation. Eve's rocking stretcher is probably the best method, though equipment may not be available and a single-handed manual method should be learnt by those whose work exposes them to risks. The Holger Nielsen method has been generally acclaimed as superior to the others. In cases where consciousness has been lost, and there are burns or the heart beat is irregular, hospital admission should be sought.

After rescue artificial respiration should be begun without delay and continued, as necessary, in the ambulance. Although in the recent reports of H.M. Chief Electrical Inspector of Factories there are no records of recovery after more than one hour's artificial respiration, success has been attained after three and even four hours. It is claimed by some that artificial respiration should continue until rigor mortis sets in. From published figures artificial respiration is successful in $67 \%$ of cases within the first 30 minutes, and in a further $8 \%$ of cases between 30 and 60 minutes, though had there been more persistence greater success might have been attained. There is some evidence that occasional beats or half beats occur, perhaps three or four a minute, which may just enable life to be supported with well-oxygenated blood, pending resumption of a normal rhythm. On admission to hospital artificial respiration should be continued and pure oxygen administered. If an electrocardiogram or an intracardiac needle shows fibrillation acetylcholine in doses of $1 \mathrm{mg}$. may be injected intracardially and repeated if necessary. 
Burns should be covered with a clean sheet and the patient evacuated to hospital with minimal delay. For the first two hours burns cases travel well, and a journey of up to this time is justifiable to reach a hospital with a burns unit. The present trend is excision of necrotic lesions and grafting. $\mathrm{By}$ conservative treatment a surprising amount of function has been regained in individual cases, though at some risk to life from toxaemia and secondary haemorrhage. Sequestra may form in necrotic bone in such cases and need removal.

In less severe cases where there may be coldness and pulselessness of a limb reassurance is necessary that this effect will last only a few hours. Arc-eye, pains, and stiffness may be persistent and need hospital examination and treatment. The most outstanding symptom in many cases is fear quite out of proportion to the severity of the accident, and this effect is found only when a current has passed through the body. Men with necrosis and flash burns, where the damage may have been very severe, may cheerfully resume duties, but in many cases of electric shock much reassurance and modification of duties may be necessary in order to rehabilitate the man. This dread (found similarly after electric convulsion therapy) may be most difficult to treat, and pyschotherapy may be indicated.

Other patients with more persistent symptoms due to angina or nervous lesions require symptomatic treatment and reassurance, and some authorities recommend a routine electrocardiogram in all cases of shock.

\section{Medico-Legal Aspects}

It is wise to avoid a hasty presumption of death with an apparently lifeless patient; cases have occurred where a workman has been revived despite the doctor's pronouncement of death. Such decisions are better made in hospital after all efforts to resuscitate the man have failed.

Electricity is sometimes used in a murder bid, as in the case of a man who attempted to murder his wife by connecting one lead to a bath and the other to a soap dish Fortunately this plot was discovered. Suicide by electricity (except those cases where the person throws himself in front of an electric train) is rare except in the frankly psychotic.

Electrocution as a method of judicial execution, although widely used in the United States, is not gaining many advocates as the most merciful method.

\section{Control of Accidents}

Control of accidents is dependent on better equipment and a greater public awareness of the dangers. In the Central Electricity Authority electrocution is rare. When it occurs, it is usually on premises outside the authority's control or in the unskilled workman. The cardinal rule is to earth the apparatus and to insulate oneself.

Next article on Emergencies in General Practice."Femoral Neck Fractures and Shoulder Dislocations," by Mr. C. G. Attenborough and Mr. H. Osmond-Clarke.

Refresher Course Book.-Copies of the second volume of collected articles from the Refresher Course for General Practitioners are still available at $25 \mathrm{~s}$. (postage-inland 1s. 6d., overseas 1s.) each. The first volume is now sold out.

Clinical Pathology Book.- " Clinical Pathology in General Practice," a collection of 39 articles on clinical pathology that appeared in the Journal as part of the Refresher Course for General Practitioners, is now available, price 21s. (postage-inland 1s. 3d., overseas 9d.).

Both these volumes are obtainable from the Publishing Manager, B.M.A. House, Tavistock Square, London, W.C.1, or through any bookseller.

\section{WELLOOME MUSEUM OF ORTHOPAEDICS}

The Wellcome Museum of Orthopaedics of the Institute of Orthopaedics was opened at the Royal National Orthopaedic Hospital, Great Portland Street, London, W.1, on April 4 by Sir Henry Dale, O.M., F.R.S. The museum has been made possible by a generous grant of $£ 4,500$ from the Wellcome Trust. It will be open daily (10 a.m. -5 p.m., except Saturdays, when it closes at 12 noon) to students and other medical visitors.

Sir HENRY FloYd, chairman of the committee of management of the Institute of Orthopaedics and of the board of governors of the hospital, speaking at the opening ceremony, recalled that the institute, a part of the British Postgraduate Medical Federation of London University, was established in 1946. Not long ago, he said, certain accommodation became available and the museum was temporarily housed in this. He then paid a warm tribute to Sir Henry Wellcome, whose benefaction had created the Wellcome Trust.

Sir HenRy Dale described the new museum as efficient and elegant. It was small in dimensions but distinguished by the high quality of the exhibits and the very high level of ingenuity and scientific thought applied to make the most of the very modest amount of space which it had been possible to make available.

Dr. H. A. Sissons, the curator of the museum, emphasized that ultimately the strength of a museum depended upon the value of the scientific material, though arrangement and presentation also played their part. It was important, at least for postgraduate students, that specimens should be accompanied by clinical histories. For material which could not be represented by specimens there were slides and pictorial representations. Dr. Sissons hoped that the museum would be of research interest as well as teaching.

\section{The Museum}

The premises in which the museum is situated were formerly shops. They have been transformed to give three exhibition rooms (one of them temporary) and a laboratory, as well as a pleasant common room for students of the institute. One of the aims of the museum will be to add substance to the "shadow world" of diagnostic radiology. In its final form, the permanent collection will be arranged as a teaching museum, and the main emphasis will be on relating the clinical and radiological aspects of orthopaedic conditions to the structural changes.

Although the museum's main purpose is to assist postgraduate teaching, it is also intended to be closely connected with research in orthopaedics and related subjects. Part of its teaching function will be to show the results of current investigations, particularly those carried out in the institute. The institute already has plans for the eventual expansion of the museum.

To mark the opening a special exhibition on the pathology of bones and joints is being staged until April 27. As well as serving to illustrate the presentation methods which will characterize the museum when the permanent collection is set up, this exhibition has great intrinsic interest. Outstanding specimens have been gathered together for it from all over the country.

A number of the specimens are historic. They include ones prepared by John Hunter, Sir James Paget, and Percivall Pott, and examples of diseases rarely encountered in these chemotherapeutical days, such as the fatal cases of suppurative arthritis and acute osteomyelitis, and the bony lesions of advanced syphilis. Some of the specimens, particularly among the bone-tumour group, have both historical and modern interest, for they represent entities such as osteoid osteoma, parosteal osteosarcoma, chondromyxoid fibroma, and aneurysmal bone cyst, which have been recognized only recently. Their inclusion may bring them to the attention of people not already fully familiar with them. 